\title{
The Temperature Sensitivity of Elastic Wave Velocity at High Pressure: New Results for Molybdenum
}

\author{
Thomas S. Duffy ${ }^{1}$ and Thomas J. Ahrens \\ Seismological Laboratory, California Institute of Technology
}

\begin{abstract}
A new experimental technique is described whereby a material is heated to very high temperature $(\mathrm{T})$, shock compressed to high pressure (P) (and higher $\mathrm{T})$, and the compressional elastic wave velocity of the high $\mathrm{P}$ and $\mathrm{T}$ state is measured. This method has been applied to the high-pressure standard molybdenum at pressures between 12 and $81 \mathrm{GPa}$ and at an initial temperature of $1400^{\circ} \mathrm{C}$. The compressional velocity of Mo at $2450^{\circ} \mathrm{C}$ and $81 \mathrm{GPa}$ is found to be $7.91 \mathrm{~km} / \mathrm{s}$, compared to a calculated value of $8.36 \mathrm{~km} / \mathrm{s}$ at $81 \mathrm{GPa}$ along the $25^{\circ} \mathrm{C}$ isotherm. Data for molybdenum, a number of other metals, and a silicate yield a consistent trend which can be used to determine the scaling coefficient between compressional velocity and temperature at geophysically relevant conditions.
\end{abstract}

\section{Introduction}

Lateral variability of longitudinal and shear wave velocity has been extensively documented throughout the Earth including the upper mantle [Nataf et al., 1986], subducting slabs [Engdahl and Gubbins, 1987], the lower mantle [Dziewonski and Woodhouse, 1987], and the D" region at the base of the mantle [Wysession et al., 1992; Silver and Bina, 1993]. Tomographic studies yield compressional wave velocity $\left(V_{P}\right)$ anomalies with RMS amplitudes of $\sim 0.3-0.5 \%$ in the upper man-

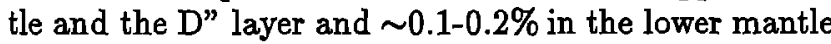
[Dziewonski and Woodhouse, 1987; Hager and Clayton, 1989]. This variability occurs on distance scales of $10^{3}$ to $10^{4} \mathrm{~km}$. If the velocity anomalies result from thermal effects, the temperature differences driving mantle convection could be inferred. However, the relationship between seismic velocity and temperature must be known.

The earliest interpretations [Hager and Clayton, 1989] of the seismic anomalies were based on ambient-pressure temperature coefficients of velocity which tended to minimize the temperature differences driving mantle convection. There are few experimental constraints on the pressure dependence of this quantity. Ultrasonic

\footnotetext{
${ }^{1}$ Now at Geophysical Laboratory, Carnegie Institution of Washington, Washington, DC 20015.
}

Copyright 1994 by the American Geophysical Union.

Paper number 94GL00223

0094-8534/94/94GL-00223\$03.00 laboratory techniques have long been used to measure the temperature coefficient of compressional velocity, $\left(\partial V_{P} / \partial T\right)_{P}$, in metals and minerals, but only a few of these studies have been conducted at simultaneous high pressure and temperature, and these were limited to conditions of the Earth's crust [e.g., Spetzler, 1970]. The temperature dependence of the elastic constants is due to the anharmonic nature of the lattice vibrations. A decrease in the temperature dependence is the expected result of the reduction of anharmonicity with pressure [Zharkov and Kalinin, 1971]. Anelasticity may also play an important role in the temperature dependence of seismic wave velocities, particularly for shear waves [Karato, 1993].

Recently, compressional wave velocities obtained under shock compression from a $25^{\circ} \mathrm{C}$ initial state were used to infer temperature coefficients of velocity by comparing shock measurements at $\mathrm{P}>50 \mathrm{GPa}$ and $\mathrm{T}$ $>1500^{\circ} \mathrm{C}$ with room temperature ultrasonic data extrapolated to high pressure [Duffy and Ahrens, 1992]. Results for $\mathrm{Al}, \mathrm{Cu}, \mathrm{W}, \mathrm{Ta}$, and the high-pressure phases of $\mathrm{Mg}_{2} \mathrm{SiO}_{4}$ indicate that $\left|\left(\partial V_{P} / \partial T\right)_{P}\right|$ decreases by a factor of $\sim 5$ (for $\mathrm{Cu}, \mathrm{Al}$, and $\mathrm{Mg}_{2} \mathrm{SiO}_{4}$ ) relative to ambient values at $P \sim 100 \mathrm{GPa}$, which is equivalent to a depth of $2250 \mathrm{~km}$ in the Earth. These data are subject to uncertainties due to extrapolation of the ultrasonic data and uncertainties in the calculated shock temperatures. In this study, these problems are overcome by pre-heating the sample to a known high temperature prior to compression.

\section{Experiments and Results}

Molybdenum (Mo) was chosen for initial study because of its role as a high-pressure standard. Shock compression of Mo ( $99.95 \%$ purity) was achieved by planar impact of aluminum and tantalum flyer plates with velocities between 0.95 and $2.28 \mathrm{~km} / \mathrm{s}$ (Fig. 1a). Prior to impact, the samples were heated to near $1400^{\circ} \mathrm{C}$ using a radio-frequency heating system [Miller et al., 1988], and the temperature was measured to $\pm 1^{\circ} \mathrm{C}$ by a Pt-Pt10\%Rh thermocouple. The velocity of the rear surface of the Mo sample was measured using a timeresolved interferometer (VISAR) [Barker and Hollenbach, 1972]. The VISAR records the Doppler shift of reflected laser light induced by motion of a diffuse reflecting surface. The time resolution of the instrument is $\sim 2-3 \mathrm{~ns}$, the precision is $\pm 1 \%$, and velocity changes of a few $\mathrm{m} / \mathrm{s}$ are resolvable. This represents the first study in which elastic properties have been measured 
a)

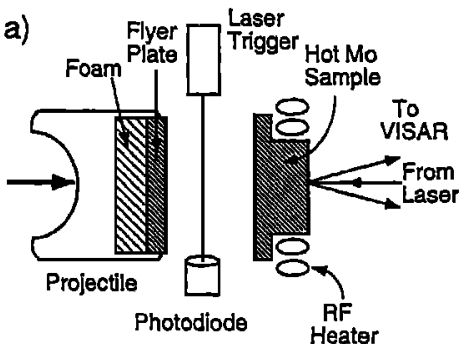

b)

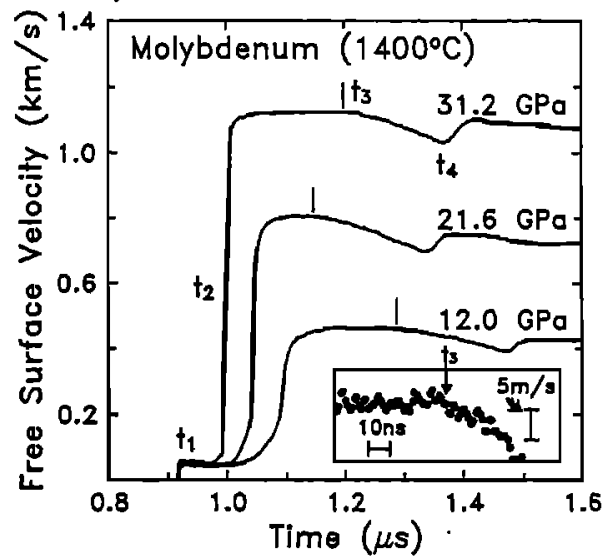

Figure 1. (a) Cross-section of experimental arrangement. (b) Particle-velocity histories recorded at the rear surface of $1400^{\circ} \mathrm{C} \mathrm{Mo}$. The pressure is indicated above each profile. The time histories are characterized by an elastic precursor $\left(t_{1}\right)$, a shock front $\left(t_{2}\right)$, initial arrival of the rarefaction $\left(t_{3}\right)$, and partial unloading which is interrupted by spallation $\left(t_{4}\right)$. Rarefaction arrivals $\left(t_{3}\right)$ are indicated by vertical lines above each profile. Inset shows an expanded view of the $31.2 \mathrm{GPa}$ profile near time $t_{3}$.

on a shock-compressed material at a significantly high $\left(>250^{\circ} \mathrm{C}\right)$ initial temperature.

Wave profiles for three experiments are shown in Fig. $1 \mathrm{~b}$. The compressive portion consists of an elastic precursor followed by the shock front. The elastic precursor velocity was calculated from the linear modulustemperature trend in high $\mathrm{T}$ ultrasonic data [Dickinson and Armstrong, 1967]. The time difference between the precursor and the midpoint of the shock establishes the shock wave velocity. The Hugoniot equation of state from this and previous data [Miller et al., 1988] is: $U_{S}$ $=4.78(0.02)+1.42(0.02) u_{p}$, where $U_{S}$ and $u_{p}$ are the shock and particle velocities, respectively.

Decompression of the sample results from a rarefaction wave propagating from the rear of the impactor (Fig. 1b, Fig. 2 (inset)). For an elastic-plastic solid, the head of the rarefaction propagates with the compressional wave velocity [Zel'dovich and Razier, 1967]. Compressional velocities in Mo to $81 \mathrm{GPa}$ determined from rarefaction wave arrivals are shown in Fig. 2. The elastic wave velocities were calculated from the rarefaction arrival time using the known shock and release properties of the impactors as well as shock and precursor velocities in Mo. The $1400^{\circ} \mathrm{C}$ Hugoniot velocities are offset to significantly lower values than ambient

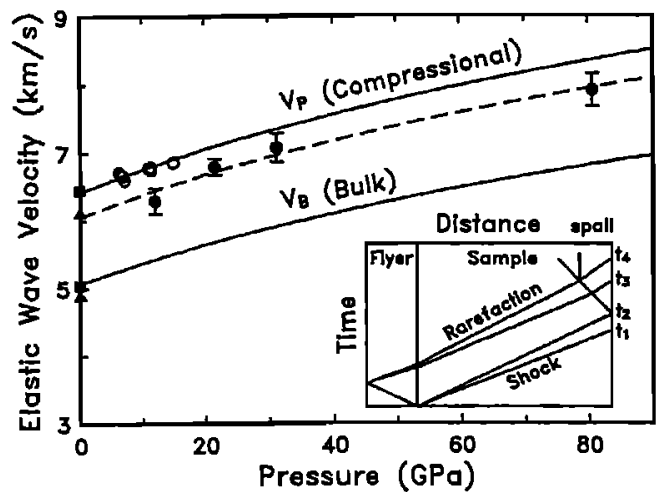

Figure 2. Elastic wave velocity in molybdenum shockcompressed at $25^{\circ} \mathrm{C}$ (open circles) and at $1400^{\circ} \mathrm{C}$ (filled circles). Calculated compressional and bulk velocities at $25^{\circ} \mathrm{C}$ are shown as solid lines. The dashed line is fit to the $1400^{\circ} \mathrm{C}$ Hugoniot velocities using Birch's Law and the Hugoniot pressure equation. Triangles show extrapolated $1400^{\circ} \mathrm{C}$ velocities at $1 \mathrm{bar}$. Inset is a distancetime diagram (in Lagrangian coordinates) of wave propagation through the flyer and sample. Arrival times $\left(t_{1}-t_{4}\right)$ correspond to those in Fig. $1 b$.

temperature ultrasonic data to $0.5 \mathrm{GPa}$ [Katahara et al., 1979] extrapolated via finite strain theory. The decrease results from the effect of temperature which reduces the elastic wave velocity. However, the measured velocities lie well above extrapolated bulk velocities.

The temperature coefficient of $V_{P}$ is calculated from the Hugoniot and room temperature data at a given pressure:

$$
\left(\partial V_{P} / \partial T\right)_{P}=\frac{V_{P}(H)-V_{P}\left(25^{\circ} C\right)}{T(H)-25^{\circ} C}
$$

where $H$ refers to Hugoniot conditions. $T(H)$ reflects both the initial temperature and the calculated shockinduced temperature increase [Duffy and Ahrens, 1992] which ranges from $129 \pm 22^{\circ} \mathrm{C}$ at $12 \mathrm{GPa}$ to $1037 \pm$ $186^{\circ} \mathrm{C}$ at $81 \mathrm{GPa}$.

The temperature coefficients of velocity for Mo are plotted in Fig. 3 together with values for other materials from room $T$ shock compression [Duffy and Ahrens, 1992]. The high-pressure Mo values are consistent with the ambient-pressure value of $\left(\partial V_{P} / \partial T\right)_{P}$ from ultrasonics [Dickinson and Armstrong, 1967] and suggest a decrease in the magnitude of this quantity with pressure. The highest pressure Mo data yield a $31-38 \%$ decrease in $\left|\left(\partial V_{P} / \partial T\right)_{P}\right|$ from $-0.26 \mathrm{~m} / \mathrm{s} /{ }^{\circ} \mathrm{C}$ at ambient pressure to $-0.16 \mathrm{~m} / \mathrm{s} /{ }^{\circ} \mathrm{C}(31 \mathrm{GPa})$ and $-0.18 \mathrm{~m} / \mathrm{s} /{ }^{\circ} \mathrm{C}$ $(81 \mathrm{GPa})$.

Comparison of Hugoniot sound velocity measurements to ambient $\mathrm{T}$ ultrasonic data is only appropriate if the extrapolation of the ultrasonic data is reliable. To examine this, Hugoniot sound velocities have been computed from wave profiles on Mo samples shocked from $25^{\circ} \mathrm{C}$ to $7-15 \mathrm{GPa}$ [Furnish and Chhabildas, 1992], a region where shock heating effects are small. As shown in Fig. 2, the Hugoniot measurements are consistent with ultrasonic data. Similar agreement between ex- 


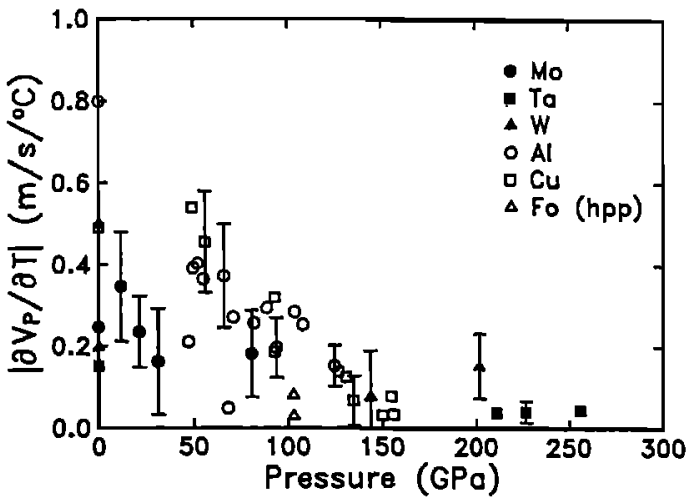

Figure 3. Temperature coefficient of compressional velocity as a function of pressure. Solid circles are present results for Mo. Data for other materials are from Duffy and Ahrens [1992]. Selected error bars are shown. Fo (hpp) is the high-pressure phase(s) of forsterite which are taken to be an equimolar mixture of $\mathrm{MgO}$ and $\mathrm{MgSiO}_{3}$-perovskite [Syono et al., 1981].

trapolated ultrasonic and Hugoniot data to $35 \mathrm{GPa}$ has been observed for $\mathrm{Al}, \mathrm{Cu}, \mathrm{W}$, and $\mathrm{MgO}$ [Duffy and Ahrens, 1992; 1994]. This provides convincing evidence that, at least for pressures on the order of a few 10s of $\mathrm{GPa}$, comparison of Hugoniot and extrapolated ultrasonic compressional velocities is appropriate. A significant advantage of preheating is that comparisons can be made at lower pressure than when the entire temperature rise is from shock heating. This minimizes errors resulting from extrapolation. A second advantage is that the precisely known initial temperature $( \pm 0.1 \%)$ constitutes $60-90 \%$ of the total temperature while the relatively poorly known $( \pm 20 \%)$ shock temperature rise contributes only $10-40 \%$, reducing the uncertainty due to shock heating. That the results are consistent with previous interpretation [Duffy and Ahrens, 1992] of Hugoniot sound velocity data from a $25^{\circ} \mathrm{C}$ initial state provides support for the assumptions made in that analysis.

Two other complications regarding Hugoniot sound velocities should be discussed. Reflection of the shock from the Mo rear surface perturbs a region near the free surface of the sample through which the rarefaction wave must pass (Fig. 2, inset). This uncertainty was minimized by including a correction term and restricting the perturbed region to less than $10 \%$ of the sample thickness. It has also been argued from micromechanical theory [Johnson et al., 1992] that, due to plastic flow, the measured Hugoniot rarefaction velocity can be less than the elastic wave velocity. The comparison shown in Fig. 2 suggests this is not the case for Mo. However, if this effect is significant, the values of $\left|\left(\partial V_{P} / \partial T\right)_{P}\right|$ obtained here would be upper bounds and the pressure dependence of this quantity would be larger than we have inferred.

\section{Discussion}

Fig. 3 demonstrates that velocity-temperature coefficients at high $\mathrm{P}$ are less than ambient-pressure values for a wide range of materials. Compressional velocities in the dense, incompressible metals (Mo, $\mathrm{Ta}, \mathrm{W}$ ) are a factor of 2-4 less sensitive to temperature at ambient conditions than those in the more compressible materials $\left(\mathrm{Al}, \mathrm{Cu}, \mathrm{Mg}_{2} \mathrm{SiO}_{4}\right)$. For the former, the velocitytemperature scaling factor decreases with pressure at a rate that is about an order of magnitude less than for the latter. The net result is that for all materials investigated, $\left|\left(\partial V_{P} / \partial T\right)_{P}\right|<0.4 \mathrm{~m} / \mathrm{s} /{ }^{\circ} \mathrm{C}$ above $50 \mathrm{GPa}$ and $\left|\left(\partial V_{P} / \partial T\right)_{P}\right|<0.2 \mathrm{~m} / \mathrm{s} /{ }^{\circ} \mathrm{C}$ above $110 \mathrm{GPa}$ (Fig. 3). Data for forsterite shocked to its high-pressure phases yield $\left(\partial V_{P} / \partial T\right)_{P} \sim-0.1 \mathrm{~m} / \mathrm{s} /{ }^{\circ} \mathrm{C}$ above $100 \mathrm{GPa}$ [Duffy and Ahrens, 1992].

The temperature coefficient of velocity relative to its ambient pressure value can be expressed as a power law function of compression: $\left(\partial V_{P} / \partial T\right)_{P} /\left(\partial V_{P} / \partial T\right)_{P=0}=$ $\left(\rho_{0} / \rho\right)^{x}$ where $\rho$ is the density (Fig. 4). Values of $x$ between 2 and 7 describe most of the current data. Fig. 4 also implies that $x$ is material dependent, which highlights the need for more measurements on materials of direct geophysical relevance. The scatter in the data for a given material is an indication of the experimental uncertainty. On the basis of the current data set, we conclude that the temperature coefficient of $V_{P}$ is less than $50 \%$ of its ambient-pressure value for a compression corresponding to the base the Earth's mantle, while it is plausibly $60-90 \%$ of its ambient value at a compression corresponding to the top of the lower mantle (Fig. 4).

An estimate of $\left(\partial V_{P} / \partial T\right)_{P}$ in the Earth's lower mantle can be made from dynamic flow models [Hager and Clayton, 1989; Ricard et al., 1989] which are constructed by translating seismic velocity anomalies into density anomalies and are tested by comparison with plate tectonics and gravity data. The results of Hager and Clayton [1989] yield a range of scaling coefficients between velocity and density which are appropriate for the lower mantle: $\left(\partial V_{P} / \partial \rho\right)_{P}=2-3(\mathrm{~km} / \mathrm{s}) /\left(\mathrm{g} / \mathrm{cm}^{3}\right)$, consistent with Birch's Law [Birch, 1961]. Combining

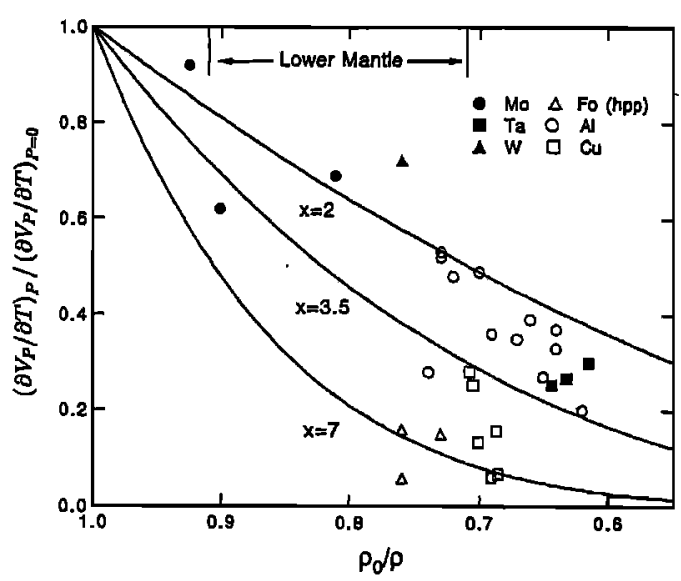

Figure 4. The temperature coefficient of velocity relative to its ambient value versus compression. Solid lines are fits using various power law exponents. The range of compression for the lower mantle was obtained by assuming a decompressed lower mantle density of 4.0 $\mathrm{g} / \mathrm{cm}^{3}$. 
these with estimates of lower mantle thermal expansivities [Duffy and Ahrens, 1993] and densities [Dziewonski and Anderson, 1981] implies that $\left(\partial V_{P} / \partial T\right)_{P} \sim-0.33$ $\mathrm{m} / \mathrm{s} /{ }^{\circ} \mathrm{C}$ at the top of the lower mantle and $\sim-0.14$ $\mathrm{m} / \mathrm{s} /{ }^{\circ} \mathrm{C}$ at its base. This is consistent with the trend reported here (Fig. 3). However, values of $\left(\partial V_{P} / \partial \rho\right)_{P}$ vary considerably between models [e.g., Ricard et al., 1989] and the density anomalies might not be entirely thermal in origin.

The shock determination of $\left(\partial V_{P} / \partial T\right)_{P}=-0.1 \pm 0.1$ $\mathrm{m} / \mathrm{s} /{ }^{\circ} \mathrm{C}$ for metals and silicate above $100 \mathrm{GPa}$ (Fig. 3 ) implies that $0.1-0.2 \%$ RMS seismic velocity anomalies in the deep lower mantle [Dziewonski and Woodhouse, 1987] correspond to thermal variations of $\sim 100$ $200^{\circ} \mathrm{C}$ and $\sim 0.4 \%$ compressional wave velocity variations in the D" region imply RMS lateral temperature variations of order $400^{\circ} \mathrm{C}$. Other seismic observations [Wysession et al., 1992] suggest lateral variations in seismic velocity of $\pm 1 \%$ in $D^{\prime \prime}$ at scale lengths of $10^{2}$ $10^{3} \mathrm{~km}$ which could correspond to thermal anomalies with amplitudes of $\pm 1000^{\circ} \mathrm{C}$ at these lengths. However, the $D^{\prime \prime}$ region is expected to be compositionally heterogeneous [Wysession et al., 1992] and attributing the seismic variations entirely to temperature is questionable. Assuming an average lower mantle temperature of $2500^{\circ} \mathrm{C}$, the compressional velocity variations imply RMS long-wavelength temperature anomalies of $6( \pm 2) \%$ in the deep lower mantle. Small-scale anomalies could be larger as tomographic results are spatially averaged. Previous studies [Hager and Clayton, $1989]$ which have neglected the pressure dependence of $\left(\partial V_{P} / \partial T\right)_{P}$ give temperature anomalies of $\sim 1 \%$. This study provides new evidence that the lower mantle is more thermally heterogeneous than previously believed.

Acknowledgments. We thank R. Jeanloz, P. Silver, C. Bina, M. Manghnani, and D. L. Anderson for constructive comments and $M$. Furnish for providing us with copies of his data. This work was supported by the NSF. Division of Geological and Planetary Sciences, California Institute of Technology contribution 5197 .

\section{References}

Barker, L. M. and R. E. Hollenbach, Laser interferometer for measuring high velocities of any reflecting surface, $J$. Appl. Phys., 43, 4669-4675, 1972.

Birch, F., The velocity of compressional waves in rocks to 10 kilobars 2, J. Geophys. Res., 92, 2199-2224, 1961.

Dickinson, J. M. and P. E. Armstrong, Temperature dependence of the elastic constants of molybdenum, J. Appl. Phys., 38, 602-606, 1967.

Duffy, T.S. and T. J. Ahrens, Sound velocities at high pressure and temperature and their geophysical implications, J. Geophys. Res., 97, 4503-4520, 1992.

Duffy, T.S. and T. J. Ahrens, Thermal expansion of mantle and core materials at very high pressure, Geophys. Res. Lett, 20, 1103-1106, 1993.

Duffy, T. S. and T. J. Ahrens, Shock compression and release of polycrystalline magnesium oxide, Proceedings of the AIRAPT Conf. on High-Pressure Science and Technology, edited by S. Schmidt, in press, 1994.
Dziewonski, A. M. and D. L. Anderson, Preliminary reference Earth model, Phys. Earth Planet. Int., 25, 297-356, 1981.

Dziewonski, A. M. and J. H. Woodhouse, Global images of the Earth's interior, Science, 236, 37-48, 1987.

Engdahl, E. R. and D. Gubbins, Simultaneous travel time inversion for earthquake location and subduction zone structure in the central Aleutian islands, J. Geophys. Res., 92, 13,855-13,862, 1987.

Furnish, M. D. and L. C. Chhabildas, Dynamic material properties of refractory materials: Molybdenum, in High Strain Rate Behavior of Refractory Metals and Alloys, edited by R. Asfahani, E. Chen, and A. Crowson, pp. 229240, The Minerals, Metals, and Materials Society, 1992.

Hager, B. H., and R. W. Clayton, Constraints on the structure of mantle convection using seismic observations, flow models, and the geoid, in Mantle Convection: Plate Tectonics and Global Dynamics, edited by W. R. Peltier, pp. 657-764, Gordon and Breach, New York, 1989.

Johnson, J. N., R. S. Hixson, G. T. Gray, and C. E. Morris, Quasielastic release in shock-compressed solids, J. Appl. Phys., 72, 429-441, 1992.

Karato, S., Importance of anelasticity in the interpretation of seismic tomography, Geophys. Res. Lett., 20, 16231626, 1993.

Katahara, K. W., M. H. Manghnani, and E. S. Fisher, Pressure derivatives of the elastic moduli of $\mathrm{BCC} \mathrm{Ti}-\mathrm{V}-\mathrm{Cr}, \mathrm{Nb}-$ Mo, and Ta-W alloys, J. Phys. F: Metal Phys., 9, 773-790, 1979.

Miller, G. H., T. J. Ahrens, and E. M. Stolper, The equation of state of molybdenum at $1400^{\circ} \mathrm{C}, J$. Appl. Phys., 69, 4469-4475, 1988.

Nataf, H.-C., I. Nakanishi, and D. L. Anderson, Measurement of mantle wave velocities and inversion for lateral heterogeneities and anisotropy 3. Inversion, J. Geophys. Res., 91, 7261-7307, 1986.

Ricard, Y., C. Vigny, and C. Froidevaux, Mantle heterogeneities, geoid, and plate motion - a Monte-Carlo inversion, J. Geophys. Res., 94, 13,739-13,754, 1989.

Silver, P. G., and C. Bina, An anomaly in the amplitude ratio of SKKS/SKS in the range $100-108^{\circ}$ from portable teleseismic data, Geophys. Res. Lett., 20, 1135-1138, 1993. Spetzler, H., Equation of state of polycrystalline and singlecrystal $\mathrm{MgO}$ to 8 kilobars and $800 \mathrm{~K}, J$. Geophys. Res., 75, 2073-2087, 1970.

Syono, Y., T. Goto, H. Takei, M. Tokonami, and K. Nobugai, Dissociation reaction in forsterite under shock compression, Science, 214, 177-179, 1981.

Wysession, M. E., E. A. Okal, and C. R. Bina, The structure of the core-mantle boundary from diffracted waves, $J$. Geophys. Res., 97, 8749-8764, 1992.

Zel'dovich, Ya. B. and Yu. P. Razier, Physics of Shock Waves and High-Temperature Hydrodynamic Phenomena, 916 pp., Academic, New York, 1967.

Zharkov, V. and V. Kalinin, Equations of State for Solids at High Pressures and Temperatures, 257 pp., Consultants Bureau, New York, 1971.

T. S. Duffy and T. J. Ahrens, Lindhurst Laboratory of Experimental Geophysics, Seismological Laboratory, California Institute of Technology, Pasadena, CA 91125.(e-mail: duffy@gl.ciw.edu)

(received November 10, 1993; accepted December 13, 1993.) 